during recent years is clearly brought out, and UK growers should not overestimate their competitors or underestimate their own strengths and advantages.

The trend in horticulture, as in other businesses, is towards cooperation and amalgamation. The difficulties that the small-scale growers, distributors and retailers have been facing will intensify, and the inefficient will be forced to leave the industry. This trend is recognized by the universities, who are paying increasing attention to management techniques and economics, and not merely to horticultural science, in the education of future managers for the large production and distribution organizations. This aspect of the industry-the education of future leaders-is hardly dealt with in the book, yet it will profoundly influence the speed and direction of development. Horticulture is usually regarded as a synonym for the intensive production of agricultural crops, and it is interpreted so in this book. It must not be forgotten, however, that amenity horticulture will continue to be increasingly important in human affairs as the prosperity of the United Kingdom and Europe grows. In addition to producing ornamental plants, horticulturists will be closely concerned with the planning and maintenance of the environment, especially in urban areas.

It was not the intention of the editors to present a "blueprint for future policymaking", but to help horticulturists and the public to see where the industry stands today, and the direction in which it is likely to move tomorrow. They succeed, for the book is readable and is not overweighted with statistics and jargon. It can be recommended to all who are interested in food production in Britain and the well-being of one of the country's basic industries. $\quad$ L. BROADBENT

\section{The Simplest Reductant}

The Hydrated Electron. By Edwin J. Hart and Michael Anbar. Pp. xiii +267. (Wiley Interscience: New York and London, October 1970.) 125s.

Alrhough solvated electrons in liquid ammonia and similar solvents had been recognized for many years, it was not until 1962 that conclusive evidence was obtained for the existence of the hydrated electron as a definite species with characteristic properties. It had been known for some time that irradiated aqueous solutions contained two different reducing species, sometimes described as different "kinds" of hydrogen atom, but the identification of one of these as a hydrated electron $\left(\mathrm{e}_{\mathrm{aq}}^{-}\right)$had to await the demonstration that it possessed a negative charge and a strong optical absorption spectrum which resembled that of the ammoniated electron, and F-centres in crystals. During the past eight years there has been intense activity in following up this discovery, especially in studying the reactions of $\mathrm{e}_{\mathrm{aq}}^{-}$ with inorganic and organic species. The Hydrated Electron quotes some 400 references which bear witness to this flood of new knowledge.

This field of research has a strange aspect to the student of conventional mechanisms and kinetics in solution. Typical concentrations of $\mathrm{e}_{a q}^{-}$are $10^{-7} \mathrm{M}$, and its concentration can be measured down to $10^{-9} \mathrm{M}$, so that trace impurities are often of great importance. Sixteen different reactions are required to account for the disappearance of $\mathrm{e}_{\mathrm{aq}}^{-}$ in pure water, and because of its transient nature, any reaction with a solute species having a second-order velocity constant less than $10^{6} 1 . \mathrm{mol}^{-1} \mathrm{~s}^{-1}$ is termed "slow", and may be difficult to detect. A combination of pulse radiolysis and competition methods has made it possible to measure the rate constants of some $\mathbf{4 0 0}$ reactions, many of them of the order of $10^{10} \mathrm{l} \cdot \mathrm{mol}^{-1} \mathrm{~s}^{-1}$, and techniques have been developed to study transient species in periods as short as $2 \times 10^{-11}$ seconds. Because $\mathrm{e}_{\mathrm{aq}}^{-}$is the simplest reducing agent, its reactions are of great interest, and considerable progress has been made in understanding the large amount of experimental information now available.

Dr Hart and Dr Anbar have made important contributions to the study of the subject and their book gives a comprehensive account of our present knowledge of the hydrated electron, including its physical properties and its reactions in inorganic, organic and biological systems. It concludes with a chapter on experimental techniques and a number of useful numerical tables. Although the preface speaks of the importance of the subject in general chemical education, the amount of detail provided is certainly too great for the non-specialist student, and the book is more suitable for those intending to enter research in this field. There are some signs of hasty preparation or proof reading : for example, "electron offinity", "cabonylic", "vandate", "triagonal", "assymmetry", "concieve", "proprionitrile", "developes" and "nitrozobenzene". In general, however, the exposition is clear and is supplemented by excellent diagrams and chapter summaries.

\section{R. P. BELL}

\section{Material Images}

Modern Diffraction and Imaging Techniques in Material Science. Edited by S. Amelinckx, R. Gevers, G. Remaut and J. Van Landuyt. Pp. viii + 745. (NorthHolland: Amsterdam and London, 1970.) 252s.

For many years now, summer schools dealing with various branches of physics have been held in Europe. In 1969, the first session devoted to materials science was held at Antwerp and dealt with diffraction and imaging techniques. The lectures from this conference have now been collected and published. The topics covered include transmission, scanning and mirror electron microscopy, low and high energy electron diffraction, X-ray and neutron diffraction, X-ray topology and field ion microscopy. In each case, the theory of diffraction or imaging, the experimental techniques, and the various applications are described in a particularly coherent way. The list of contributors includes many of the most eminent names in modern diffraction.

At the outset it needs to be said that there are two ways in which materials scientists use these modern techniques. The first is in an observational way, analogous to the way in which an optical microscope is used. In many cases what one is seeing is obvious, so that with only a limited knowledge, transmission and scanning electron microscopy or X-ray topology can be used quite successfully. The second way of using these diffractional and imaging techniques goes far beyond the simple observational approach. It involves using the techniques in a most sophisticated manner, applying diffraction theory to interpret what are often very complicated images and patterns. That is what this book is about.

The book starts with a treatment of the kinematical and dynamical theory of electron diffraction, and the application of dynamical theory to line defects in order to calculate intensity profiles. This approach is then extended by a chapter dealing with the use of computer simulation techniques to produce "dot" pictures, like newsprint, which can be directly compared with the images seen in the electron microscope. Among other topics, there is a fascinating discussion of Kikuchi lines in transmission electron microscopy which demonstrates the power of the electron microscope for accurate diffraction studies. In scanning electron microscopy, which rightly takes up a good part of this book, the analogue to Kikuchi lines is the electron channelling patterns, which are extremely important, for they represent the one way of observing crystallographic effects. The problems, and the experimental conditions for obtaining them, are clearly described.

Although many of the topics in this book are treated in a general way, several pieces of information are included which cannot readily be found in the literature, and which should prove most valuable to the researcher working on his own. This poses an interesting question. Who outside of the prominent research groups will utilize in an advanced way these powerful techniques? Certainly not the average materials scientist. Nevertheless, this book may prove of value to the adventurous researcher working in isolation.
E. Lilley 